\title{
Evaluation of enhanced external counterpulsation therapy for nonarteritic anterior ischemic optic neuropathy
}

\author{
Lixia Lin ${ }^{1+} \mathbb{D}$, Wenhui Zhu ${ }^{2 \dagger}$, Nan Ma', Xiaofeng Lin ${ }^{1 *}$ and Hui Yang ${ }^{1 *}$
}

\begin{abstract}
Background: To explore the effects of enhanced external counterpulsation (EECP) and its underlying influencing factors in nonarteritic anterior ischemic optic neuropathy (NAION) patients.

Methods: Patients at Zhongshan Ophthalmic Center with recent-onset ( $<8$ weeks) NAION were retrospectively recruited. The patients had decided whether or not they would undergo EECP treatment, and the patients who declined were included in the control group. The effectiveness of EECP was evaluated by comparing the visual function and fellow eye involvement in patients with and without EECP treatment.

Results: In total, 61 patients (76 eyes) were included. Twenty-nine patients (37 eyes) underwent EECP treatment, while 32 patients (39 eyes) were included in the control group. Mean time from NAION onset to EECP initiation was $27.59 \pm 16.70$ days. In the EECP group, the mean EECP duration was $31.57 \pm 18.45$ days. EECP was well tolerated by all patients. However, there was no significant difference in visual function between the EECP and control groups. Furthermore, there was no evidence of the effectiveness of EECP in the subgroup analysis of patients with different systemic health conditions. Among the 42 patients with monocular NAION, the sequential attack rate was comparable between the EECP (27.78\%) and control (25.00\%) groups.

Conclusion: This study is the first nonrandomized controlled study to evaluate the effectiveness of EECP in NAION patients. Unfortunately, we failed to demonstrate the effectiveness of EECP in NAION at the 6-month follow-up. Any further application of EECP in NAION patients should be cautious.
\end{abstract}

Keywords: Nonarteritic anterior ischemic optic neuropathy, Enhanced external counterpulsation, Visual acuity, Visual field

\section{Background}

Nonarteritic anterior ischemic optic neuropathy (NAION) is an acute vision-threatening neurologic disorder commonly seen in elderly people [1]. Typically, the vision loss is usually monocular but, in some cases, binocular vision loss occurs in sequence or even simultaneously [2]. The precise pathogenesis of NAION is unclear. A variety of potential

\footnotetext{
* Correspondence: linxiaof@mail.sysu.edu.cn; 13710584767@163.com

${ }^{\dagger}$ Lixia Lin and Wenhui Zhu contributed equally to the present study and were regarded as equivalent authors.

'Zhongshan Ophthalmic Center, State Key Laboratory of Ophthalmology, Sun Yat-sen University, Guangzhou 510060, China

Full list of author information is available at the end of the article
}

NAION risk factors can cause regional hypoxemia-related disc edema, resulting in axon death [3]. Some researchers have suggested that NAION is caused by circulatory insufficiency of the short posterior ciliary arteries, leading to laminar infarction of the optic nerve [4]. Several interventions have been proposed based on this theory [3-5]. The prognosis of NAION is still very poor, although the visual acuity improvement is relatively common. Moreover, no treatment has been shown to be substantially effective for vision function restoration or prevention of fellow eye involvement $[5,6]$.

(c) The Author(s). 2020 Open Access This article is licensed under a Creative Commons Attribution 4.0 International License, which permits use, sharing, adaptation, distribution and reproduction in any medium or format, as long as you give appropriate credit to the original author(s) and the source, provide a link to the Creative Commons licence, and indicate if changes were made. The images or other third party material in this article are included in the article's Creative Commons licence, unless indicated otherwise in a credit line to the material. If material is not included in the article's Creative Commons licence and your intended use is not permitted by statutory regulation or exceeds the permitted use, you will need to obtain permission directly from the copyright holder. To view a copy of this licence, visit http://creativecommons.org/licenses/by/4.0/ The Creative Commons Public Domain Dedication waiver (http://creativecommons.org/publicdomain/zero/1.0/) applies to the data made available in this article, unless otherwise stated in a credit line to the data. 
Enhanced external counterpulsation (EECP) involves a noninvasive mechanical circulatory support system and it is used as an adjunctive therapy in patients with ischemic vascular diseases [7]. Using inflatable cuffs around the lower limbs, EECP increases the aortic diastolic pressure and cardiac output by increasing the venous volume return to the heart, leading to increased reperfusion of the affected arteries. Considering the "ischemic nature" of NAION, we previously investigated the use of EECP in NAION patients, which showed promising short-term results in improvement of visual acuity [8]. However, to the best of our knowledge, no controlled study with long-term follow-up and detailed visual function results has been reported regarding the effectiveness of EECP in NAION patients. Hence, this study was conducted to further explore the long-term benefit of EECP and its underlying influencing factors in NAION patients, by comparing the clinical outcomes of patients treated with and without EECP.

\section{Methods}

The study was approved by the Ethics Committee of Zhongshan Ophthalmic Center. The study adhered to the Declaration of Helsinki. Patients with recent-onset (<8 weeks) NAION were retrospectively recruited from the neuro-ophthalmology department of Zhongshan Ophthalmic Center. NAION diagnosis was made according to the Ischemic Optic Neuropathy Decompression Trial (IONDT) diagnostic criteria [9].

Detailed data from the patients' medical records were collected, including medical history, medication usage history, and ophthalmic examination results: bestcorrected vision acuity (BCVA), funduscopy, visual field (VF), fundus fluorescein angiography (FFA), visual evoked potential (VEP), and optical coherence tomography (OCT) results. Other routine assessments, including a blood pressure assessment, comprehensive blood tests, brain magnetic resonance imaging (MRI), and carotid artery color ultrasound imaging, had been conducted for each NAION patient (to exclude other diagnoses). Data from these assessments were collected retrospectively from the medical records to evaluate systemic health conditions (i.e., hypertension, diabetes mellitus, hypercholesterolemia, and ischemic stroke and etc.).

After the potential benefits and safety of EECP was explained by an ophthalmologist in detail, the patients had voluntarily decided whether or not to undergo EECP. The patients who had not elected to undergo EECP were included in the control group. After providing informed signed consent for EECP treatment, EECP patients attended the EECP Center at the First Affiliated Hospital of Sun Yat-sen University (Guangzhou, China), where they were scheduled to attend 1-h daily EECP sessions for up to 2 months. Patients were allowed to withdraw from treatment at any time. If any adverse event was reported, the clinician could also discontinue EECP.

All the patients, including EECP patients, were prescribed vitamin B12 and citicoline for at least 2 months. Patients with systemic risk factors were advised to continue receiving medical care from related specialists at the same time. Biweekly neuro-ophthalmology visits were scheduled until 2 months after NAION onset, followed by bimonthly visits for another 4 months. Detailed ophthalmic examinations were conducted at every visit, except for VEP and FFA assessments, which were only conducted in the first visit.

The exclusion criteria were as follows: suspicion of toxic, infiltrative, hereditary, or compressive optic neuropathy, arteritis, or any other prior ocular condition that might affect visual acuity or the visual field; lacking 6month follow-up data; and EECP treatment $<7$ days sessions in the EECP group; EECP contradictions (history of bypass surgery, heart attack, heart failure, aortic disease, aortic insufficiency, congestive heart disease, abdominal aortic aneurysm, venous thrombosis, frequent arrhythmia, or severe peripheral vascular disease [10]).

Detailed EECP procedures have been described previously, and the same protocol was used for all the patients $[8,11]$. The EECP device (Shuangshan EECP-MCI, Guangzhou, China) inflates and deflates leg cuffs (using an air compressor) in a sequence synchronized to the patient's cardiac cycle. The compression pressure of the cuffs was $0.035-0.040 \mathrm{mPa} / \mathrm{cm}$.

\section{Statistical methods}

The data analyses were performed using SPSS 19.0 (SPSS, Chicago, IL, USA). To evaluate the effectiveness of EECP on NAION, the eyes with NAION were divided into the EECP group and control group according to whether the patients chose EECP treatment or not. For patients with sequential attacks, only the eye with recent-onset NAION was included. Baseline differences between groups were compared with the independentsamples t-test and chi-square test. The independent ttest was also employed to evaluate between-group differences in treatment outcomes at 2 and 6 months, including the change in BCVA (logMAR), change in VF (mean deviation, $\mathrm{MD}$ ) and retinal nerve fiber layer thickness (RNFLT). According to IONDT, the appropriate therapeutic window for NAION might be within 2 weeks after onset [9]. Accordingly, the EECP group was further divided into two groups: EECP within 2 weeks and EECP after 2 weeks. One-way analysis of variance (ANOVA) was employed to evaluate the differences between the control group, EECP group with EECP initiated within 2 weeks and EECP group with EECP initiated after 2 weeks. The level of significance was set at 0.05 (two tailed). 


\section{Results}

A total of 61 patients with 76 eyes from August 2015 to August 2018 were retrospectively included in this study. There were 38 (62.30\%) males and 23 (37.70\%) females. The mean age was $53.28 \pm 9.40$. Twenty-nine patients (37 eyes) underwent EECP treatment, leaving 32 participants (39 eyes) enrolled in the control group. In the EECP group, the mean time from NAION onset to EECP initiation was $27.59 \pm 13.56$ days and the mean EECP duration was $31.57 \pm 18.45$ days. No adverse events were reported.

There was no significant difference between the two groups regarding baseline characteristics (including the systemic risk factors). Detailed information is summarized in Table 1.

\section{Effect of EECP on visual function}

As shown in Table 2, there was no significant difference in the visual function between the EECP and control groups, regardless of follow-up time. The mean BCVA at presentation was $0.74 \pm 0.62$ and $0.99 \pm 1.14(P=$ 0.095) in the EECP and control groups, respectively. At month 2 , the corresponding BCVA changes were $0.02 \pm$ 0.44 and $-0.16 \pm 0.59(P=0.261)$. At month 6 , the corresponding BCVA changes were $0.04 \pm 0.51$ and $-0.02 \pm$ $0.35(P=0.264)$. The mean $\mathrm{MD}$ at presentation was $20.93 \pm 8.77$ and $-19.26 \pm 9.81(P=0.239)$ in the EECP and control groups, respectively. At month 2, the corresponding MD changes were $0.04 \pm 3.15$ and $1.57 \pm 4.38$

Table 1 Baseline characteristics and risk factors of EECP and control groups

\begin{tabular}{llll}
\hline & EECP & Control & $P$ value \\
\hline Age & $53.81 \pm 10.34$ & $54.31 \pm 9.41$ & $0.419^{\mathrm{a}}$ \\
Sex, M:F & $23: 14$ & $23: 16$ & $0.776^{\mathrm{b}}$ \\
Systemic risk factors & & & \\
Hypertension & $17(45.95 \%)$ & $15(38.46 \%)$ & $0.509^{\mathrm{b}}$ \\
Diabetes mellitus & $12(32.43 \%)$ & $19(48.72 \%)$ & $0.149^{\mathrm{b}}$ \\
Hypercholesterolemia & $13(35.14 \%)$ & $13(33.33 \%)$ & $0.869^{\mathrm{b}}$ \\
Ischemic lesion on brain MRI & $7(18.92 \%)$ & $10(25.64 \%)$ & $0.482^{\mathrm{b}}$ \\
Carotid artery plaque & $8(21.62 \%)$ & $6(15.38 \%)$ & $0.483^{\mathrm{b}}$ \\
High blood viscosity & $6(16.22 \%)$ & $4(10.26 \%)$ & $0.668^{\mathrm{b}}$ \\
Apnea & $3(8.11 \%)$ & $4(10.26 \%)$ & $0.942^{\mathrm{b}}$ \\
Anemia & $2(5.41 \%)$ & $4(10.26 \%)$ & $0.720^{\mathrm{b}}$ \\
Hepatitis B & $2(5.41 \%)$ & $4(10.26 \%)$ & $0.720^{\mathrm{b}}$ \\
Hypoxia & $3(8.11 \%)$ & $0(0.00 \%)$ & $0.220^{\mathrm{b}}$ \\
Alcoholism & $2(5.41 \%)$ & $5(12.82 \%)$ & $0.471^{\mathrm{b}}$ \\
Smoking & $0(0.00 \%)$ & $3(7.69 \%)$ & $0.258^{\mathrm{b}}$ \\
No of eyes attacked & $37(100.00 \%)$ & $39(100.00 \%)$ & \\
\hline
\end{tabular}

EECP enhanced external counterpulsation

andependent t-test

${ }^{b}$ Chi-square test
$(P=0.287)$. At month 6 , the corresponding MD changes were $0.27 \pm 3.15$ and $2.28 \pm 4.80(P=0.443)$. The mean RNFLT values at presentation were $166.63 \pm 82.01$ and $175.61 \pm 71.51(P=0.140)$ in the EECP and control groups, respectively; the corresponding values at month 6 were $65.10 \pm 21.42$ and $65.63 \pm 19.43(P=0.600)$.

Eight eyes underwent EECP within 2 weeks after NAION onset and 29 eyes initiated EECP after 2 weeks. No significant differences were observed by comparing these two groups with the control group (Table 2).

Additionally, there was no evidence of the effectiveness of EECP in the subgroup analysis of patients with different systemic health risk factors (hypertension, diabetes mellitus, hypercholesterolemia, and ischemic stroke) (Table 3).

\section{Effect of EECP on prevention of fellow eye NAION involvement}

No recurrent attack was observed in any patients. Among the 42 patients with monocular NAION, five (27.28\%) in the EECP group and six $(25.00 \%)$ in the control group $(P=0.879)$ experienced fellow eye involvement during the 6-month follow-up. The mean intervals between the two attacks were $83.40 \pm 41.57$ and $70.00 \pm$ $52.38(P=0.305)$, respectively (Table 4$)$.

\section{Discussion}

Despite years of clinical and basic science studies, the exact mechanism of NAION is still unknown [3]. Briefly, the ultimate axonal degeneration and retinal ganglion cell apoptosis are comprehensive results of vascular ischemia (which causes anterior optic nerve edema), edema in a crowded disc (which causes compartment syndrome), and a subsequent cascade of vasogenic and cytotoxic factors $[4,12]$. All these events ultimately lead to axonal degeneration and retinal ganglion cell apoptosis. Accordingly, potential therapeutic interventions targeting different parts of the pathogenic mechanism have been developed.

Histopathological and electron microscopic studies have shown that initial ischemia in the anterior optic nerve head is probably triggered by acute hypoperfusion of the vascular network originating from the short posterior ciliary arteries [13]. Previous studies have reported that not only can EECP accelerate reperfusion of the poorly perfused cerebral microvasculature and retinal artery, increase the blood flow velocity of the ophthalmic artery, but it can also improve endothelial function and collateral angiogenesis [14-16]. Additionally, EECP is thought to be highly safe and well-tolerated in selected patients [7, 17]. Therefore, EECP was expected to be a safe and effective intervention in ocular ischemic diseases. Previously, we reported in 16 NAION patients that visual acuity had improved from 0.92 to 0.40 (LogMAR) after EECP treatment ( $1 \mathrm{~h}$ daily for 12 days) [8]. 
Table 2 Visual function differences among groups at baseline and 2- and 6-month follow-up

\begin{tabular}{|c|c|c|c|c|c|c|c|}
\hline & Total & Control group & EECP group & $\begin{array}{l}\text { EECP initiated } \\
\text { within } 2 \text { weeks }\end{array}$ & $\begin{array}{l}\text { EECP initiated } \\
\text { after } 2 \text { weeks }\end{array}$ & $\begin{array}{l}P \text { value }{ }^{a} \\
\text { (t-test) }\end{array}$ & $\begin{array}{l}P \text { value } \\
\text { (ANOVA) }\end{array}$ \\
\hline & 76 & 39 & 37 & 8 & 29 & & \\
\hline \multicolumn{8}{|l|}{ BCVA } \\
\hline Baseline & $0.87 \pm 0.93$ & $0.99 \pm 1.14$ & $0.74 \pm 0.62$ & $0.66 \pm 0.48$ & $0.76 \pm 0.65$ & 0.095 & 0.492 \\
\hline Month 2 & $0.79 \pm 0.72$ & $0.82 \pm 0.68$ & $0.76 \pm 0.76$ & $0.80 \pm 0.52$ & $0.75 \pm 0.83$ & 0.954 & 0.926 \\
\hline Change (2-0) & $-0.07 \pm 0.52$ & $-0.16 \pm 0.59$ & $0.02 \pm 0.44$ & $0.15 \pm 0.25$ & $-0.01 \pm 0.47$ & 0.261 & 0.211 \\
\hline Month 6 & $0.75 \pm 0.61$ & $0.72 \pm 0.51$ & $0.77 \pm 0.72$ & $0.83 \pm 0.92$ & $0.67 \pm 0.62$ & 0.174 & 0.145 \\
\hline Change (6-0) & $0.01 \pm 0.43$ & $-0.02 \pm 0.35$ & $0.04 \pm 0.51$ & $0.21 \pm 0.32$ & $-0.05 \pm 0.41$ & 0.264 & 0.054 \\
\hline \multicolumn{8}{|l|}{ MD } \\
\hline Baseline & $-20.09 \pm 9.27$ & $-19.26 \pm 9.81$ & $-20.93 \pm 8.77$ & $-18.97 \pm 7.07$ & $-21.48 \pm 9.24$ & 0.239 & 0.602 \\
\hline Month 2 & $-19.28 \pm 9.05$ & $-17.69 \pm 9.41$ & $-20.88 \pm 8.50$ & $-18.76 \pm 8.74$ & $-21.77 \pm 8.49$ & 0.459 & 0.248 \\
\hline Change (2-0) & $0.81 \pm 3.86$ & $1.57 \pm 4.38$ & $0.04 \pm 3.15$ & $0.22 \pm 2.48$ & $-0.01 \pm 3.35$ & 0.287 & 0.244 \\
\hline Month 6 & $-19.52 \pm 9.09$ & $-19.21 \pm 9.89$ & $-20.27 \pm 7.24$ & $-16.75 \pm 15.91$ & $-20.37 \pm 5.71$ & 0.096 & 0.798 \\
\hline Change (6-0) & $1.30 \pm 4.15$ & $2.28 \pm 4.80$ & $0.27 \pm 3.15$ & $1.37 \pm 5.98$ & $0.07 \pm 4.15$ & 0.443 & 0.290 \\
\hline \multicolumn{8}{|l|}{ RNFLT } \\
\hline Baseline & $170.99 \pm 76.65$ & $175.61 \pm 71.51$ & $166.63 \pm 82.01$ & $155.42 \pm 69.87$ & $169.68 \pm 85.65$ & 0.140 & 0.801 \\
\hline Month 2 & $77.76 \pm 29.40$ & $81.44 \pm 25.66$ & $73.23 \pm 33.48$ & $82.00 \pm 59.11$ & $71.27 \pm 27.31$ & 0.835 & 0.511 \\
\hline Month 6 & $65.35 \pm 20.24$ & $65.63 \pm 19.43$ & $65.10 \pm 21.42$ & $57.67 \pm 16.20$ & $66.34 \pm 22.30$ & 0.600 & 0.796 \\
\hline
\end{tabular}

EECP enhanced external counterpulsation, $B C V A$ best-corrected visual acuity in LogMAR, MD mean deviation, RNFLT retinal nerve fiber layer thickness ${ }^{\mathrm{a}}$ Independent t-test comparing visual function between the EECP and control groups

'One way ANOVA comparing the control group, EECP group with EECP initiated within 2 weeks and EECP group with EECP initiated after 2 weeks

However, the study did not have a control group. Therefore, the current controlled study with detailed examinations and a long follow-up period was deemed necessary to further evaluate the safety and long-term benefits of EECP treatment for NAION.

Unfortunately, this study demonstrated no obvious long-term benefit of EECP treatment in NAION patients with NAION onset $<8$ weeks, regarding visual function and risk of fellow eye involvement. During the treatment period, which was no less than the treatment durations in the previous EECP studies reporting promising results regarding angina [7, 17-19], the safety of EECP was confirmed.

IONDT reported that around $40 \%$ of NAION patients might spontaneously regain 3-line visual acuity, which might explain the paradox involving the current study and our previous study, as the improvement in our previous study was probably not attributable to EECP [20]. There are few other studies on the effectiveness of EECP in NAION patients. One such study reported significant visual acuity improvement after EECP treatment in patients with carotid artery stenosis-related ocular ischemic diseases, including ischemic optic neuropathy (which includes more conditions than NAION), retinal artery occlusion, and ocular ischemic syndrome [16]. The study did not include a control group and the curative rate for the ischemic optic neuropathy subgroup was not reported.
Thus, the effectiveness of EECP of NAION has not been proven.

Among the therapies tested in NAION patients, aspirin and anticoagulants have been acted on thrombosis and both vasopressors and vasodilators have been proposed to be useful for regulating vasodynamic factors [6, 21-24]. Although they all aimed to resolve the initial triggers of disc edema, there was no visual function improvement from any of the treatments. Considering the results of the current study, we speculate that interventions targeting the pathophysiological factors that are relevant prior to disc edema might not be helpful for improving visual function. Once disc edema is triggered, a destructive closed loop may be formed by a cascade of events, including compartment syndrome with axonal and capillary compression, increased ischemia, increased release of cytotoxic factors, and vasogenic and cytotoxic disc edema $[4,25,26]$. Future interventions should pay more attention to disrupting this loop. Furthermore, novel NAION animal models have recently emerged, which will help researchers to evaluate new drugs [27].

As stated by Newman et al., one of the most important approaches regarding NAION management is to reduce the risk of fellow eye involvement [6]. To protect against fellow eye involvement, potential etiological factors should be corrected first [6]. As mentioned above, EECP can accelerate reperfusion and increase the blood flow 
Table 3 Comparisons of the visual function of the EECP and control groups by systemic health condition

\begin{tabular}{|c|c|c|c|c|c|c|c|c|}
\hline & Hypertension & & Diabetes mellitus & & Hyperc & rolemia & Ischemic stroke & \\
\hline & Yes & No & Yes & No & Yes & No & Yes & No \\
\hline No. of eyes & 32 & 44 & 31 & 45 & 26 & 50 & 17 & 59 \\
\hline EECP/Control (n) & $17 / 15$ & $20 / 24$ & $12 / 19$ & $25 / 20$ & $13 / 13$ & $24 / 26$ & $7 / 10$ & $30 / 29$ \\
\hline \multicolumn{9}{|l|}{ BCVA } \\
\hline \multirow[t]{2}{*}{ Baseline } & $0.019^{a}$ & 0.921 & 0.065 & 0.625 & 0.626 & 0.086 & 0.059 & 0.102 \\
\hline & $\begin{array}{l}0.99 \pm 0.70 \text { vs } \\
1.17 \pm 1.07\end{array}$ & & & & & & & \\
\hline \multirow[t]{2}{*}{ Month 2} & 0.885 & 0.650 & 0.917 & 0.826 & 0.178 & 0.661 & $0.035^{\mathrm{a}}$ & 0.777 \\
\hline & & & & & & & $\begin{array}{l}0.62 \pm 0.26 \text { vs } \\
0.95 \pm 0.46\end{array}$ & \\
\hline Change (2-0) & 0.122 & 0.800 & 0.087 & 0.511 & 0.759 & 0.308 & 0.204 & 0.265 \\
\hline Month 6 & 0.651 & 0.091 & 0.069 & 0.911 & 0.063 & 0.195 & 0.096 & 0.051 \\
\hline Change (6-0) & 0.250 & 0.274 & 0.065 & 0.847 & 0.778 & 0.244 & 0.163 & 0.089 \\
\hline \multicolumn{9}{|l|}{ MD } \\
\hline Baseline & 0.063 & 0.901 & 0.153 & 0.797 & 0.394 & 0.453 & 0.849 & 0.134 \\
\hline \multirow[t]{2}{*}{ Month 2} & $0.038^{\mathrm{a}}$ & 0.422 & 0.106 & 0.662 & 0.814 & 0.474 & 0.650 & 0.425 \\
\hline & $\begin{array}{l}-21.88 \pm 7.02 \text { vs } \\
-19.18 \pm 10.55\end{array}$ & & & & & & & \\
\hline Change (2-0) & 0.490 & 0.139 & 0.758 & 0.096 & 0.128 & 0.799 & 0.240 & 0.155 \\
\hline \multirow[t]{2}{*}{ Month 6} & 0.069 & 0.620 & $0.031^{\mathrm{a}}$ & 0.885 & 0.744 & 0.056 & 0.096 & 0.200 \\
\hline & & & $\begin{array}{l}-20.98 \pm 5.79 \text { vs } \\
-18.92 \pm 10.58\end{array}$ & & & & & \\
\hline Change (6-0) & 0.609 & 0.911 & 0.202 & 0.244 & 0.425 & 0.715 & 0.748 & 0.460 \\
\hline \multicolumn{9}{|l|}{ RNFLT } \\
\hline \multirow[t]{2}{*}{ Baseline } & 0.910 & $0.013^{a}$ & 0.083 & 0.346 & 0.914 & 0.074 & 0.217 & 0.072 \\
\hline & & $\begin{array}{l}170.63 \pm 80.25 \text { vs } \\
189.38 \pm 82.58\end{array}$ & & & & & & \\
\hline Month 2 & 0.385 & 0.137 & 0.329 & 0.295 & 0.162 & 0.666 & 0.295 & 0.689 \\
\hline Month 6 & 0.827 & 0.089 & 0.417 & 0.616 & 0.054 & 0.715 & 0.448 & 0.096 \\
\hline
\end{tabular}

EECP enhanced external counterpulsation, BCVA best-corrected visual acuity in LogMAR, MD mean deviation, RNFLT retinal nerve fiber layer thickness Independent t-test was conducted to compare visual function between EECP and control groups

${ }^{a}$ Detailed parameter descriptions (EECP group vs control group) are displayed for cases involving a significant difference

velocity of the ophthalmic artery, which might improve the vascular circulation of the fellow eye and theoretically prevent fellow eye involvement. However, EECP did not show any protective effect regarding fellow eye involvement in this study. The rate of sequential attack during the 6-month follow-up period was relatively high (25-28\%) compared to that in other studies (15-20\%) $[28,29]$. This might be explained by the fact that patients without fellow eye involvement can easily be lost to follow-up after stabilization of the visual acuity in the first eye. As a result, the rate of fellow eye involvement identified in this retrospective study might be much higher than the actual rate. As optic nerves are the nerve endings of the cerebrum, many consider NAION and intracranial cerebrovascular ischemic disease to be similarly related [30]. Consequently, long-term aspirin use has also been recommended by some practitioners as a secondary prevention method, despite the controversy regarding the current evidence [22]. A large randomized controlled trial is necessary to provide more credible evidence.

As a retrospective study, some limitations were inevitable in the current study. As the patients had chosen whether or not to undergo EECP treatment freely, this may have led to unrecognized bias, even though there were no significant differences regarding baseline characteristics (including the risk factors) between the two groups. Although there is no definite therapeutic window for NAION treatment, many studies have specified a 2-week window $[9,31,32]$. Most patients in current study had exceeded 2-week window at presentation. In order to rule out the time of treatment as a confounding factor, comparison was made to observe the difference between the eight eyes underwent EECP within the 
Table 4 Comparison of NAION patterns between the two groups

\begin{tabular}{lll}
\hline Pattern & EECP & Control \\
\hline Simultaneous binocular attack & $3(6)$ & $3(6)$ \\
Sequential attacks (only the recent-onset eye was included) & $8(8)$ & $5(5)$ \\
Presented with monocular attack & $18(23)$ & $24(28)$ \\
Sequential fellow eye attack & $5(10)$ & $6(10)^{\mathrm{a}}$ \\
Interval between two attacks (d) & $83.40 \pm 41.57$ & $70.00 \pm 52.38$ \\
$\quad$ Fellow eye intact & $13(13)$ & $18(18)$ \\
Total & $29(37)$ & $32(39)$
\end{tabular}

NAION non-arteritic anterior ischemic optic neuropathy, EECP enhanced external counterpulsation

Data show the no. of subjects (no. of eyes)

aTwo subjects were lost to follow-up after fellow eye attack

${ }^{b}$ Chi-square test, which was conducted with the no. of subjects

${ }^{c}$ Independent t-test

2-week therapeutic window and the 29 underwent EECP after this window. Even though no differences were observed, the issue remains to be a limitation should be emphasized. After all, effort was devoted to improving the current frustrating situation regarding NAION treatment, but no significant effects were observed after EECP treatment.

\section{Conclusion}

This study is the first controlled study with a long-term follow-up period to evaluate the effectiveness of EECP treatment in NAION patients and to assess its prevention effect on fellow eye involvement. By comparing the groups with and without EECP treatment, we failed to demonstrate the effectiveness of EECP in NAION patients with onset $<8$ weeks. A randomized controlled trial with prompt EECP treatment is recommended, until then, any further application of EECP in NAION patients should be cautious.

\section{Abbreviations \\ NAION: Nonarteritic anterior ischemic optic neuropathy; EECP: Enhanced external counterpulsation; IONDT: Ischemic Optic Neuropathy \\ Decompression Trial; BCVA: Best-corrected vision acuity; VF: Visual field; FFA: Fundus fluorescein angiography; VEP: Visual evoked potential; OCT: Optical coherence tomography; MRI: Magnetic resonance imaging}

\section{Acknowledgements}

Not Applicable.

\section{Authors' contributions}

$L X L, W H Z, N M, X F L$, and $H Y$ were all involved in the conception and design of the study. $\mathrm{WHZ}$ and $\mathrm{HY}$ were responsible for conducting the patient treatment in the clinical practice. NM had collected the data. LXL and XFL had analyzed the patient data and were also major contributors in writing the manuscript. All authors read and approved the final manuscript.

\section{Funding}

This study was supported in part by several funds, which are listed below. National Natural Science Foundation of China (81870656) paid for paper publication fee;

The Natural Science Foundation of Guangdong Province (2017A030313610) paid for professional language editing fee;

The Bethune and Langmu Ophthalmologic Research Fund (BJ-I.M2016002J) paid for data analysis fee;
Fundamental Research Funds of the State Key Laboratory of Ophthalmology $(30,306,020,240,020,130,3,030,902,113,030)$ both paid for data analysis fee.

\section{Availability of data and materials}

The datasets generated during and analyzed during the current study are not publicly available due to patient privacy but are available from the corresponding author on reasonable request.

\section{Ethics approval and consent to participate}

The study was approved by the Ethics Committee of Zhongshan Ophthalmic Center. As a retrospective study, patient consent to participate the study were waived by the Ethic Committee. However, signed consent were obtained for those patients underwent EECP treatment. No administrative permissions or licenses were acquired to access the data used in this study, which was abtained diretly from neuro-ophthalmology department of Zhongshan Ophthalmic Center.

\section{Consent for publication}

Not Applicable.

\section{Competing interests}

The authors declare that they have no competing interests.

\section{Author details}

'Zhongshan Ophthalmic Center, State Key Laboratory of Ophthalmology, Sun Yat-sen University, Guangzhou 510060, China. ${ }^{2}$ Department of Ophthalmology, The First Affiliated Hospital of Sun Yat-sen University, Guangzhou, China.

Received: 17 January 2020 Accepted: 9 June 2020

Published online: 17 June 2020

\section{References}

1. Kerr NM, Chew SS, Danesh-Meyer HV. Non-arteritic anterior ischaemic optic neuropathy: a review and update. J Clin Neurosci. 2009;16(8):994-1000.

2. Keren S, Zanolli M, Dotan G. Visual outcome following bilateral non-arteritic anterior ischemic optic neuropathy: a systematic review and meta-analysis. BMC Ophthalmol. 2017;17(1):155.

3. Hayreh SS. Ischemic optic neuropathies - where are we now? Graefes Arch Clin Exp Ophthalmol. 2013;251(8):1873-84.

4. Biousse V, Newman NJ. Ischemic optic neuropathies. N Engl J Med. 2015; 372(25):2428-36

5. Foroozan R. New treatments for nonarteritic anterior ischemic optic neuropathy. Neurol Clin. 2017;35(1):1-15.

6. Atkins EJ, Bruce BB, Newman NJ, Biousse V. Treatment of nonarteritic anterior ischemic optic neuropathy. Surv Ophthalmol. 2010;55(1):47-63.

7. Linnemeier G, Rutter MK, Barsness G, Kennard ED, Nesto RW, Investigators I. Enhanced external counterpulsation for the relief of angina in patients with diabetes: safety, efficacy and 1-year clinical outcomes. Am Heart J. 2003; 146(3):453-8. 
8. Zhu W, Liao R, Chen Y, Liu L, Zhang Y. Effect of enhanced extracorporeal counterpulsation in patients with non-arteritic anterior ischaemic optic neuropathy. Graefes Arch Clin Exp Ophthalmol. 2015;253(1):127-33.

9. The ischemic optic neuropathy decompression trial (IONDT): design and methods. Control Clin Trials 1998, 19(3):276-296.

10. Arora RR, Chou TM, Jain D, Fleishman B, Crawford L, McKiernan T, Nesto RW. The multicenter study of enhanced external counterpulsation (MUST-EECP): effect of EECP on exercise-induced myocardial ischemia and anginal episodes. J Am Coll Cardiol. 1999;33(7):1833-40.

11. Luo C, Liu D, Wu G, Hu C, Zhang Y, Du Z, Dong Y. Effect of enhanced external counterpulsation on coronary slow flow and its relation with endothelial function and inflammation: a mid-term follow-up study. Cardiology. 2012;122(4):260-8.

12. Luneau K, Newman NJ, Biousse V. Ischemic optic neuropathies. Neurologist. 2008;14(6):341-54

13. Knox DL, Kerrison JB, Green WR. Histopathologic studies of ischemic optic neuropathy. Trans Am Ophthalmol Soc. 2000;98:203-20 discussion 221-202.

14. Werner D, Michalk F, Harazny J, Hugo C, Daniel WG, Michelson G. Accelerated reperfusion of poorly perfused retinal areas in central retinal artery occlusion and branch retinal artery occlusion after a short treatment with enhanced external counterpulsation. Retina. 2004;24(4):541-7.

15. Werner D, Michalk F, Hinz B, Werner U, Voigt JU, Daniel WG. Impact of enhanced external counterpulsation on peripheral circulation. Angiology. 2007:58(2):185-90.

16. Yang $Y$, Zhang $H$, Yan $Y$, Gui $Y$. Clinical study in patients with ocular ischemic diseases treated with enhanced external counterpulsation combined with drugs. Mol Med Rep. 2013;7(6):1845-9.

17. Raza A, Steinberg K, Tartaglia J, Frishman WH, Gupta T. Enhanced external counterpulsation therapy: past, present, and future. Cardiol Rev. 2017;25(2): 59-67.

18. Amin F, Al Hajeri A, Civelek B, Fedorowicz Z, Manzer BM. Enhanced external counterpulsation for chronic angina pectoris. Cochrane Database Syst Rev. 2010;(2):CD007219.

19. Sharma U, Ramsey HK, Tak T. The role of enhanced external counter pulsation therapy in clinical practice. Clin Med Res. 2013;11(4):226-32.

20. Dickersin K, Everett D, Feldon S, Hooper F, Kaufman D, Kelman S, Langenberg P, Newman NJ, Wilson PD, Zam ZS, Kennerdell J. Optic nerve decompression surgery for nonarteritic anterior ischemic optic neuropathy (NAION) is not effective and may be harmful. The Ischemic Optic Neuropathy Decompression Trial Research Group. JAMA. 1995;273(8):625-32

21. Aftab AM, lqbal M, Rauf A, Ali A. Non arteritic anterior ischemic optic neuropathy; does anticoagulation help? J Ayub Med Coll Abbottabad. 2016; 28(4):776-80.

22. Beck RW, Hayreh SS, Podhajsky PA, Tan ES, Moke PS. Aspirin therapy in nonarteritic anterior ischemic optic neuropathy. Am J Ophthalmol. 1997; 123(2):212-7.

23. Haas A, Walzl M, Jesenik F, Walzl B, Berghold A, Bergloff J, Feigl B, Faulborn J. Application of HELP in nonarteritic anterior ischemic optic neuropathy: a prospective, randomized, controlled study. Graefes Arch Clin Exp Ophthalmol. 1997;235(1):14-9.

24. Kollarits CR, McCarthy RW, Corrie WS, Swann ER. Norepinephrine therapy of ischemic optic neuropathy. J Clin Neuroophthalmol. 1981;1(4):283-8.

25. Prescott CR, Sklar CA, Lesser RL, Adelman RA. Is intravitreal bevacizumab an effective treatment option for nonarteritic anterior ischemic optic neuropathy? J Neuroophthalmol. 2012;32(1):51-3.

26. Hayreh SS, Zimmerman MB. Optic disc edema in non-arteritic anterior ischemic optic neuropathy. Graefes Arch Clin Exp Ophthalmol. 2007;245(8): 1107-21.

27. Peeler C, Cestari DM. Non-arteritic anterior ischemic optic neuropathy (NAION): a review and update on animal models. Semin Ophthalmol. 2016; 31(1-2):99-106.

28. Newman NJ, Scherer R, Langenberg P, Kelman S, Feldon S, Kaufman D, Dickersin K, Ischemic Optic Neuropathy Decompression Trial Research G. The fellow eye in NAION: report from the ischemic optic neuropathy decompression trial follow-up study. Am J Ophthalmol. 2002;134(3):317-28.

29. Chang MY, Keltner JL. Risk factors for fellow eye involvement in nonarteritic anterior ischemic optic neuropathy. J Neuroophthalmol. 2019;39(2):147-52.

30. Arnold AC. Ischemic optic neuropathy. In: Miller NR, Newman NJ, Biousse V, et al., editors. Clinical neuro-ophthalmology, vol. 1. 6th ed. Philadelphia: Williams \& Wilkins; 2005
31. Pakravan $M$, Sanjari $N$, Esfandiari $H$, Pakravan $P$, Yaseri $M$. The effect of highdose steroids, and normobaric oxygen therapy, on recent onset nonarteritic anterior ischemic optic neuropathy: a randomized clinical trial. Graefes Arch Clin Exp Ophthalmol. 2016;254(10):2043-8.

32. Wilhelm B, Ludtke $H$, Wilhelm $H$, Group BS. Efficacy and tolerability of $0.2 \%$ brimonidine tartrate for the treatment of acute non-arteritic anterior ischemic optic neuropathy (NAION): a 3-month, double-masked, randomised, placebo-controlled trial. Graefes Arch Clin Exp Ophthalmol. 2006:244(5):551-8

\section{Publisher's Note}

Springer Nature remains neutral with regard to jurisdictional claims in published maps and institutional affiliations.
Ready to submit your research? Choose BMC and benefit from:

- fast, convenient online submission

- thorough peer review by experienced researchers in your field

- rapid publication on acceptance

- support for research data, including large and complex data types

- gold Open Access which fosters wider collaboration and increased citations

- maximum visibility for your research: over $100 \mathrm{M}$ website views per year

At BMC, research is always in progress.

Learn more biomedcentral.com/submissions 